\title{
Trading off Tourism for Fisheries
}

\author{
Bui Bich Xuan ${ }^{\mathrm{a},{ }^{*}}$ \& Claire W. Armstrong ${ }^{\mathrm{b}}$ \\ ${ }^{a}$ Economic Faculty, Nha Trang University, 02 Nguyen Dinh Chieu, Nha Trang, Vietnam \\ ${ }^{b}$ Norwegian College of Fishery Science, UiT The Arctic University of Norway, 9037 Troms $\phi$, \\ Norway * Corresponding author. \\ Email address: xuanbb@ntu.edu.vn (B.B.Xuan).
}

\section{Acknowledgments}

We would like to thank Ola Flaaten, Ngoc Quach Thi Khanh for their valuable comments on previous versions of the paper. Thanks to Erlend Dancke Sandorf and Margrethe Aanesen also, for their collaboration. Funding from the Norwegian Agency for Development Cooperation (NORAD) is acknowledged. 


\title{
Trading off Tourism for Fisheries
}

\begin{abstract}
This paper presents a deterministic bioeconomic model in which the creation of a marine protected area (MPA) is not only a fisheries management tool but also introduced in order to provide tourism amenity benefits. The theoretical model is illustrated with analysis of the Nha Trang Bay (NTB) MPA in Khanh Hoa province in Vietnam, where the anchovy purse seine fishery is considered. An amenity value function of the NTB MPA is estimated from a discrete choice experiment (DCE) among national tourists. A weighting parameter is added to the bioeconomic model to allow the establishment of a tradeoff between management preferences regarding the two sectors affected by the MPA, fisheries and tourism. Both the theoretical models and the empirical application show how the added amenity values affect optimal fishing practices as well as the identification of the optimal MPA size. Our applied analysis shows that contrary to the argument in most MPA studies with multiple stakeholders, the current management practice in Khanh Hoa prioritizes the fisheries sector heavily compared to tourism, despite high economic cost.
\end{abstract}

Keywords: Marine Protected Area, Fishery, Tourism, Bioeconomic Model, Management 


\section{Introduction}

Marine protected areas (MPAs) have often been established for the purpose of protecting and recovering biodiversity and habitats (Balmford et al., 2004), and hence have also been seen as an alternative fisheries management tool ( Rodwell et al., 2003). Restoration of marine biodiversity and seascapes of sub-marine areas due to such protection is also attractive for tourism and other recreational activities (Alban et al., 2008). In this way, MPAs are not only a management tool for fisheries, but they may also provide amenity values via resources for tourism development or recreation. In this paper, we present a bioeconomic model to capture both extractive (e.g. fisheries) and non-extractive (e.g. tourism) values generated by MPAs. We find the optimal trade-off between fisheries and tourism, and compare it to the actual trade-off existing in the current management in Khanh Hoa province, Vietnam.

In the economic literature, a few studies combine extractive and non-extractive value, or use and non-use value, to capture multiple benefits accruing from wildlife both in relation to terrestrial and marine resources. For instance, Alexander (2000) presents a bioeconomic model using the African elephant as an example, in order to estimate the use and non-use value of endangered species. He shows that non-consumptive value (i.e. tourism revenue) and non-use value (i.e. existence value) can be used to support elephant conservation, and hence play an important role in slowing population decline. Skonhoft (2007) uses a bioeconomic model taking into account both consumptive and non-consumptive value to analyze the conflict of interests between a park agency and local people, related to terrestrial wildlife conservation. Rondeau (2001) includes a valuation function in a bioeconomic model for deer, in order to discuss wildlife management with multiple objectives. Bulte et al. (1998) and Horan \& Shortle (1999) integrate non-use values of Minke whale 
stocks in a bioeconomic model of harvesting in order to study the optimal management of whale resources. The results of these two studies suggest that the Minke whale moratorium was inefficient when only market values (i.e. whale hunting) were considered. However when there is significant non-use value, a moratorium could be optimal. Moyle \& Evans (2008) included tourism values of whale watching in a model to inform policy, and discuss issues related to the economic benefits of switching from whale hunting to watching._Armstrong et al. (2017) use an expanded bioeconomic model to show how non-use value of natural habitats impacts on optimal fishing activities, using cold water corals in Norway as an example. Hence, a combination of multiple benefits accruing from natural resource use may give different economic implications than predicted in the studies solely focusing on commercial harvest (Boncoeur et al., 2002).

Despite these many examples of non-use values of natural resources, very few studies have been carried out in order to investigate multiple benefits provided by protection of natural environments in for instance MPAs (Boncoeur et al., 2002; Lee and Iwasa, 2011), and even fewer using empirical data for model application (see one exception in Merino et al., 2009). Boncoeur et al. (2002) used a bioeconomic model, which combines both a marine reserve and multi-species modeling, to analyze the impacts of MPA creation on both fishing and ecotourism. In the same vein, Merino et al. (2009) presented a bioeconomic model that permits the partial evaluation of a three-zone MPA system as regards coexistence of fisheries and tourism activities. Lee \& Iwasa (2011) also used bioeconomic models to analyze and discuss the conflicts of interests between tourists as anglers and local fishers, as well as how to reduce these conflicts.

Differing from these earlier studies on multi-benefits provided by MPAs, the tourism values included in our bioeconomic model are derived from a DCE. We surveyed tourists' preferences regarding biodiversity conservation obtained via the expansion of an MPA, an approach that to 
our knowledge has not been applied in the development of a bioeconomic MPA model earlier (see however Armstrong et al. (2017) who insert non-use values estimated from a DCE regarding cold water coral protection into a bioeconomic model of optimal management of interactions between renewable and non-renewable resources). Furthermore, MPA size is in this model explicitly considered as one of the control variables together with the harvest. This is a novel contribution as to the best of our knowledge no existing study of the multi-use provided by an MPA has accounted for the question of optimal size of an MPA in the context of overall_optimal management. In economic analysis of MPAs so far, studies have mostly focused on the species (see however Boncoeur et al., 2002; Merino et al., 2009; Lee \& Iwasa, 2011), and the issues of biodiversity has not been given economic weight (Armstrong, 2007). Hence, we add a specific weighting parameter in our model to assess the trade-off between preferences of different stakeholders (a similar model by Skonhoft \& Johannesen, 2000, was used to study reindeer herding). The distributional issues connected to the management of multi-use of natural resources are also discussed in our study. In addition, the application of our model is illustrated by empirical data from both the anchovy purse seine fishery in the south-central part of Vietnam, and tourism valuation of the Nha Trang Bay (NTB) MPA. The conflicts of interest between tourism and fisheries in relation to MPA development have especially been studied in developing economies (Christie, 2004; Oracion et al., 2005) but also in developed countries (Badalamenti et al., 2000), where the main argument is that management has not sufficiently taken into account fishery community interests. Our results for the Khanh Hoa fishery-tourism interaction show the opposite outcome; the existing management highly prioritizes the fisheries rather than tourism, and at a high opportunity cost for society overall. 
The next section in the paper presents the model specifications. An empirical application of the model is presented in the third section, including description of the study site and stakeholders, data, and simulation results. The paper concludes with a discussion of the results.

\section{Model specifications}

The model is based on Conrad's (1999) bioeconomic marine reserve model of fisheries, where the tourism value of MPAs is added, making it an integrated bioeconomic MPA model.

Creation of an MPA may restore the essential fish habitat (e.g., areas for breeding, spawning, nurseries, and feeding of fish), resulting in an increase in resource recruitment within the reserve relative to the nearby fishing grounds. This could imply spatial heterogeneity in the growth, for instance in the intrinsic growth rate and/or the carrying capacity of fish (Schnier, 2005), and the catchability of fish (Foley et al., 2012). Though it is not implausible that spatial heterogeneity in the growth of fish exists, it is probably more relevant for stationary, demersal species, which may to a greater degree be impacted by habitat improvement in an MPA than the migratory, pelagic anchovy. Though the catchability coefficient, $q$, has been suggested to be a decreasing function of a fishery's location's distance from an MPA (Rakitin and Kramer, 1996), we assume a constant catchability coefficient (i.e., the average catchability for the fishing ground), which again seems acceptable for the same reasons mentioned for growth.

A fraction $m, 0<m<1$, of the entire area denotes the share of the reserve zone (RZ), and $(1-m)$ is the fraction of the harvest zone (HZ), making the carrying capacities in the $\mathrm{RZ}$ and $\mathrm{HZ}$ equal to $m K$ and $(1-m) K$, respectively, where $K$ is carrying capacity of the entire area. The creation of an MPA raises the possibility of migration or diffusion if the densities of the population are different 
in the two sub-areas. We assume that there is net migration from the RZ, $M\left(X_{1}, X_{2}, m\right)=$ $\gamma\left(\frac{X_{2}}{m K}-\frac{X_{1}}{(1-m) K}\right)$, which is also the net immigration to the HZ, where $\gamma>0$ is the dispersal parameter determining fish movement between the two areas, $X_{1}$ and $X_{2}$ are fish stock in the HZ and $\mathrm{RZ}$, respectively.

The attractiveness of an MPA to tourism is mostly linked to biodiversity or density of a specific species, and the demand for MPA-based tourism is therefore often formulated as a function of fish stock (Boncoeur et al., 2002) or a combination of fish stock and MPA size (Merino et al., 2009). In this paper, the tourism value in the integrated bioeconomic MPA model, $V(m)$, is assumed to depend on the size of the RZ. The preferences of the tourists regarding the MPA size, which may for instance incorporate or be a proxy for biodiversity, are derived from a DCE survey, giving the form of the $V(m)$ function. This is described further below. The tourism value function is an increasing concave function in $m$, i.e., $V^{\prime}(m)>0$ and $V^{\prime \prime}(m)<0$.

The goal of a resource manager is to find a set of harvest, $Y$, size of RZ, $m$, and stock levels, $X_{1}$ and $X_{2}$, to maximize the total value of the resource use: $B=(1-\alpha)\left[p-c\left(X_{1}\right)\right] Y+\alpha V(m)$, where $Y$ denotes harvest, being the standard Schaefer harvest function: $Y=q E X_{1} ; c\left(X_{1}\right)=$ $c /\left(q X_{1}\right)$ is the cost of a unit harvest, where $c$ is the unit cost of effort; and $p$ is the price of fish, assumed to be constant $;^{1} \alpha$ is a weighting parameter, $\alpha \in[0,1]$, allowing the establishment of a tradeoff between management preferences of the two sectors supported by the MPA (e.g., fisheries and tourism). Hence if $\alpha$ is equal to zero the preferences of the fishery sector would be totally dominant, and vice versa with $\alpha$ equal to 1 , where the whole area would be dedicated to tourism development. A similar procedure is used in Munro's (1979) study, determining the weighting parameter between the profits of two countries harvesting a common fish stock.

The general objective function of the optimal control problem is presented as follows: 
$\max _{\langle Y, m\rangle} N P V=\int_{0}^{\infty}\left\{(1-\alpha)\left[p-c\left(X_{1}\right)\right] Y+\alpha V(m)\right\} e^{-\delta t} d t$

subject to

$$
\begin{aligned}
\dot{X}_{1} & =r X_{1}\left(1-\frac{X_{1}}{(1-m) K}\right)+\gamma\left(\frac{X_{2}}{m K}-\frac{X_{1}}{(1-m) K}\right)-Y \\
& =F_{1}\left(X_{1}, m\right)+M\left(X_{1}, X_{2}, m\right)-Y \quad, X_{1}(0)=X_{01}, X_{1}(t) \geq 0,0 \leq Y \leq Y_{\max } \\
\dot{X}_{2} & =r X_{2}\left(1-\frac{X_{2}}{m K}\right)-\gamma\left(\frac{X_{2}}{m K}-\frac{X_{1}}{(1-m) K}\right) \\
& =F_{2}\left(X_{2}, m\right)-M\left(X_{1}, X_{2}, m\right), X_{2}(0)=X_{02}, X_{2}(t) \geq 0,0 \leq m \leq 1
\end{aligned}
$$

where, $F_{1}\left(X_{1}, m\right)$ and $F_{2}\left(X_{2}, m\right)$ are the natural growth functions of the fish stock within the HZ and RZ, respectively.

In the case of $\alpha=0$, implementing an MPA is solely focused on the fishery, the maximization problem is now similar to Conrad (1999), which we call the bioeconomic fishery model of MPAs. The Hamiltonian for this problem may be expressed as follows: ${ }^{2}$

$H=e^{-\delta t}\left[p-c\left(X_{1}\right)\right] Y+\mu_{1}\left[F_{1}\left(X_{1}, m\right)+M\left(X_{1}, X_{2}, m\right)-Y\right]+\mu_{2}\left[F_{2}\left(X_{2}, m\right)-M\left(X_{1}, X_{2}, m\right)\right]$

with $\mu_{1}$ and $\mu_{2}$ being the adjoint variables measuring the shadow prices of the associated state variables $X_{1}$ and $X_{2}$.

The first order conditions for the optimal solution are:

$\frac{\partial H}{\partial Y}=e^{-\delta t}\left[p-c\left(X_{1}\right)\right]-\mu_{1}=0$

$\dot{\mu}_{1}=-\frac{\partial H}{\partial X_{1}}=e^{-\delta t} c_{X_{1}}\left(X_{1}\right) Y-\mu_{1}\left[F_{1 X_{1}}\left(X_{1}, m\right)+M_{X_{1}}\left(X_{1}, X_{2}, m\right)\right]+\mu_{2} M_{X_{1}}\left(X_{1}, X_{2}, m\right)$

$\dot{\mu}_{2}=-\frac{\partial H^{c}}{\partial X_{2}}=-\mu_{1} M_{X_{2}}\left(X_{1}, X_{2}, m\right)-\mu_{2}\left[F_{2 X_{2}}\left(X_{2}, m\right)-M_{X_{2}}\left(X_{1}, X_{2}, m\right)\right]$

Since the Hamiltonian is linear in the control variable, $Y$, there exists a singular solution, the steady-state equilibrium, when equation (5) holds. If equation (5) does not hold, the optimal policy is to drive the state variables, $X_{1}(t)$ and $X_{2}(t)$, to the singular path as rapidly as possible, which 
is traditionally coined the "bang-bang" equilibrium (Munro and Scott, 1985). Particularly, if $e^{-\delta t}\left[p-c\left(X_{1}\right)\right]-\mu_{1}>0$, then $Y=Y_{\max }$, and if $e^{-\delta t}\left[p-c\left(X_{1}\right)\right]-\mu_{1}<0$, then $Y=0$. In the case of a singular solution, the steady-state equilibrium, $\left(X_{1}^{*} ; X_{2}^{*}\right)$, must satisfy:

$\delta=F_{1 X_{1}}\left(X_{1}^{*}, m\right)+\frac{\partial B / \partial X_{1}^{*}}{\partial B / \partial Y^{*}}+M_{X_{1}}\left(X_{1}^{*}, X_{2}^{*}, m\right)\left[1+\frac{M_{X_{2}}\left(X_{1}^{*}, X_{2}^{*}, m\right)}{F_{2 X_{2}}\left(X_{2}^{*}, m\right)-M_{X_{2}}\left(X_{1}^{*}, X_{2}^{*}, m\right)-\delta}\right]$

In equilibrium, $\dot{X}_{1}=\dot{X}_{2}=0, Y=F_{1}\left(X_{1}, m\right)+M\left(X_{1}, X_{2}, m\right)$, and $F_{2}\left(X_{2}, m\right)=M\left(X_{1}, X_{2}, m\right)$, the harvest therefore equals the sum of the fish stock natural growth within the $\mathrm{HZ}$ and RZ. Equation (3) and (8) can be used to solve simultaneously for the steady-state equilibrium $\left(X_{1}^{*} ; X_{2}^{*}\right)$. The optimal harvest is $Y^{*}=F_{1}\left(X_{1}^{*}, m\right)+F_{2}\left(X_{2}^{*}, m\right)$. The net present value from fisheries in the steadystate can be calculated from the following function:

$N P V_{f}^{*}=\frac{\left[p-c\left(X_{1}^{*}\right)\right] Y^{*}}{\delta}$

In the case of $0<\alpha<1$, the MPA supports both fishery and tourism activities, and we call this the integrated bioeconomic model of MPAs. The Hamiltonian for this problem is: ${ }^{3}$

$$
\begin{gathered}
H=e^{-\delta t}\left[(1-\alpha)\left[p-c\left(X_{1}\right)\right] Y+\alpha V(m)\right]+\mu_{1}\left[F_{1}\left(X_{1}, m\right)+M\left(X_{1}, X_{2}, m\right)-Y\right] \\
+\mu_{2}\left[F_{2}\left(X_{2}, m\right)-M\left(X_{1}, X_{2}, m\right)\right]
\end{gathered}
$$

The Hamiltonian is linear in the control variable, harvest, and non-linear (i.e., strictly concave) in the control variable, RZ size, as well as the state variables, fish stocks in RZ and HZ, providing sufficient conditions for the maximum problem. The non-linearity in the control variable $m$ also implies that if $X_{1}(0) \neq X_{1}^{*}$ and $X_{2}(0) \neq X_{2}^{*}$, the optimal approach path to the stock levels, $X_{1}^{*}$ and $X_{2}^{*}$, is no longer the most rapid but will rather be asymptotic. If $X_{1}(0)=X_{1}^{*}$ and $X_{2}(0)=$ $X_{2}^{*}$, there is possibility of multiple equilibria (Munro and Scott, 1985).

The first order conditions for the equilibrium solutions are: 


$$
\begin{aligned}
& \frac{\partial H}{\partial Y}=e^{-\delta t}(1-\alpha)\left[p-c\left(X_{1}\right)\right]-\mu_{1}=0 \\
& \frac{\partial H}{\partial m}=e^{-\delta t} \alpha V_{m}(m)+\mu_{1}\left[F_{1 m}\left(X_{1}, m\right)+M_{m}\left(X_{1}, X_{2}, m\right)\right] \\
& +\mu_{2}\left[F_{2 m}\left(X_{2}, m\right)-M_{m}\left(X_{1}, X_{2}, m\right)\right]=0 \\
& \dot{\mu}_{1}=-\frac{\partial H}{\partial X_{1}}=e^{-\delta t}(1-\alpha) c_{X_{1}}\left(X_{1}\right) Y-\mu_{1}\left[F_{1 X_{1}}\left(X_{1}, m\right)+M_{X_{1}}\left(X_{1}, X_{2}, m\right)\right] \\
& +\mu_{2} M_{X_{1}}\left(X_{1}, X_{2}, m\right) \\
& \dot{\mu}_{2}=-\frac{\partial H^{c}}{\partial X_{2}}=-\mu_{1} M_{X_{2}}\left(X_{1}, X_{2}, m\right)-\mu_{2}\left[F_{2 X_{2}}\left(X_{2}, m\right)-M_{X_{2}}\left(X_{1}, X_{2}, m\right)\right]
\end{aligned}
$$

There are two joint equilibrium equations, derived from (11) and (13) as well as (12) and (14), which yield the MPA versions of the Clark \& Munro (1975) Golden Rule, as follows:

$$
\begin{aligned}
\delta= & F_{1 X_{1}}\left(X_{1}^{*}, m^{*}\right)+\frac{\partial B / \partial X_{1}^{*}}{\partial B / \partial Y^{*}} \\
& +M_{X_{1}}\left(X_{1}^{*}, X_{2}^{*}, m^{*}\right)\left[1+\frac{\alpha\left(\partial B / \partial m^{*}\right)+(1-\alpha)\left(\partial B / \partial Y^{*}\right)\left[F_{1 m}\left(X_{1}^{*}, m^{*}\right)+M_{m}\left(X_{1}^{*}, X_{2}^{*}, m^{*}\right)\right]}{(1-\alpha)\left(\partial B / \partial Y^{*}\right)\left[F_{2 m}\left(X_{2}^{*}, m^{*}\right)-M_{m}\left(X_{1}^{*}, X_{2}^{*}, m^{*}\right)\right]}\right] \\
\delta= & F_{2 X_{2}}\left(X_{2}^{*}, m^{*}\right) \\
& -M_{X_{2}}\left(X_{1}^{*}, X_{2}^{*}, m^{*}\right)\left[1+\frac{(1-\alpha)\left(\partial B / \partial Y^{*}\right)\left[F_{2 m}\left(X_{2}^{*}, m^{*}\right)-M_{m}\left(X_{1}^{*}, X_{2}^{*}, m^{*}\right)\right]}{\alpha\left(\partial B / \partial m^{*}\right)+(1-\alpha)\left(\partial B / \partial Y^{*}\right)\left[F_{1 m}\left(X_{1}^{*}, m^{*}\right)+M_{m}\left(X_{1}^{*}, X_{2}^{*}, m^{*}\right)\right]}\right]
\end{aligned}
$$

The first terms on the right hand side of (15) and (16) are referred to as the instantaneous marginal product of resources in the $\mathrm{HZ}$ and in the $\mathrm{RZ}$, respectively. The second term on the right hand side of (15) is the marginal stock effect in the HZ. The last terms on the right hand side of (15) and (16) are referred to as the marginal RZ size effect, and the larger $\alpha$ is, the greater this effect will be. Equations (2), (3), (15), and (16) can be used to solve simultaneously for the multiple equilibria $\left(X_{1}^{*}, X_{2}^{*}, m^{*}\right.$, and $\left.Y^{*}\right)$. The total net present value from both fisheries and tourism sectors at the optimum optimorum can be calculated as in the following function: ${ }^{4}$

$N P V^{*}=N P V_{f}^{*}+N P V_{v}^{*}=\frac{\left[p-c\left(X_{1}^{*}\right)\right] Y^{*}+V\left(m^{*}\right)}{\delta}$

where, $N P V_{v}^{*}$ is the net present value from tourism sector. 
We have presented the two models: the bioeconomic fishery model of MPAs (with $\alpha=0$ ) and the integrated bioeconomic model of MPAs (with $0<\alpha<1$ ). The case of $\alpha=1$ is discussed later in the discussion section of the paper.

\section{Empirical application of the model}

The fishery studied is the anchovy purse seine fishery in Khanh Hoa province, south-central Vietnam. Although fisheries in Vietnam in general and in Khanh Hoa in particular are open access, implying zero fisheries' rent, we assume the possibility of an optimally managed fishery in Khanh Hoa so as to compare the optimal situations for fisheries and tourism. ${ }^{5}$ The tourism activity applied is the tourism value of NTB MPA, located in Khanh Hoa waters, derived from a DCE survey. In the following is a short description of the study site and stakeholders, followed by a presentation of the data and the simulation results.

\subsection{Study site and stakeholders}

Khanh Hoa is a coastal province where fisheries and tourism are among the most important economic industries. Fisheries in Khanh Hoa are open access and multispecies, using various types of gears such as gill net, longline, trawl net, purse seine, and lift net. There are a total of almost 10,000 vessels fishing in Khanh Hoa waters, of which less than $8 \%$ have an engine power greater

than 90 horsepower (HP), allowing offshore fishing. ${ }^{6}$ Hence, the majority of fishing boats in Khanh Hoa are small scale and operate in the coastal zone. The annual average revenue of the fisheries is 
about 273 million USD, contributing 13.5\% to the gross domestic product (GDP) of Khanh Hoa province during the period of $2011-2015 .^{7}$

Tourist activities in Khanh Hoa are mostly characterized as island tourism. Khanh Hoa has a long coastline of $520 \mathrm{~km}$, including about 200 islands, and six bays and lagoons. The number of tourists visiting Khanh Hoa has been increasing at an average rate of 18\% annually from 2011 to 2015. The annual revenues of the tourism industry are about 243 million USD, contributing $12 \%$ of the province's GDP. In 2015, about 4.1 million tourists, of which one fourth were foreigners, visited Khanh Hoa. ${ }^{8}$

Nha Trang Bay is one of the most famous bays in Vietnam, where the first Vietnamese MPA was established in 2002. The MPA was multi-purpose, focusing on biodiversity conservation, livelihood improvement for local residents (i.e. fishermen)_in partnership with other stakeholders (Thu et al., 2005). NTB MPA has a total area of $160 \mathrm{~km}^{2}$, encompassing nine islands and surrounding waters. It has been shown to have the highest marine biodiversity in Vietnamese coastal waters and also relatively high for the Pacific Ocean overall, including a multitude of different habitats (i.e. coral reefs, seagrass beds, mangroves, sand-muddy areas, and rocky shores) (Tuan et al., 2002). Moreover, this marine area is considered a major spawning and nursery ground supporting fish larvae to other Vietnamese and possibly Cambodian waters (Dung, 2009). NTB MPA is a three-zone MPA, consisting of a core, a buffer, and a transition zone. The core zone of $16 \mathrm{~km}^{2}$ encompasses five islands: Hon Mun, Hon Rom, Hon Noc, Hon Vung and Hon Cau as well as the ocean area extending $300 \mathrm{~m}$ from the water's edge of these islands, which is protected from fishing and other activities, except for tourism. The buffer zone includes land and waters within $300 \mathrm{~m}$ of the islands; Hon Tam, Hon Tre, Hon Mieu, Hon Mot, and the additional waters of 300m surrounding the core zone. Traditional fishing gear, marine aquaculture and tourism are allowed 
in this zone, but no trawling. The rest of the NTB MPA is the transition zone, open to all activities, though limiting bottom trawl with regards to mesh size and engine power (see Figure 1). ${ }^{9}$

Figure 1 is here

The NTB MPA is not only a place for protecting marine biodiversity in general and the exploited stocks from fishing in particular, it is also one of the most popular destinations for tourists visiting Khanh Hoa province, where they can enjoy tourism activities such as diving, snorkeling, swimming, water sports, etc. The number of tourists visiting the NTB MPA has been increasing from 30 thousand people in 1995 to more than 600 thousand people in $2014 .^{10}$

\subsection{Data}

\subsubsection{The anchovy purse seine fishery data}

Because of the complexity of multi-species fisheries and limited data availability, we concentrate on the anchovy purse seine fishery in Khanh Hoa province, which operates outside the NTB MPA core zone.

Anchovies are among the most traded fish species in the world. They are a small, migratory, schooling 2 pelagic fish belonging to the Engraulidae (Mediterranean and European) and Anchoa (North America) family (FAO, 2012). Two of five commercial anchovy species (Encrasicolus and Stolephorus) are found in Vietnam (Thi et al., 2007). In Khanh Hoa province, anchovy is one of the most important inshore fisheries and is mainly fished by anchovy purse seiners_(Thuy and Flaaten, 2013). The annual operating time is about 8-10 months, divided into two seasons: high season is from February to October and low season is the remaining months (Thuy and Flaaten, 2013). Anchovies are distributed mainly in shallow coastal waters and near islands (Thi et al., 
2007). The popular fishing grounds of anchovy purse seiners are around Nha Trang and Cam Ranh Bay (Kim Anh et al., 2007).

Despite the fact that anchovies are highly migratory they have preferred coastal grounds for spawning and nursing around islands and in bays. The NTB MPA is suggested to be one of the most important spawning and nursery grounds of Khanh Hoa waters as indicated in a few studies on egg and larval distribution (Phung et al., 2002; Quang, 2008; Viet et al., 2014). These studies show that fish eggs and larvae are present at all sample stations, where the sample stations within the NTB MPA have high relative density of fish eggs and larvae, and of which anchovies make up the major component.

The biological and economic parameter values of the anchovy purse seine fishery in the model mainly come from the results of a study carried out by Thuy \& Flaaten (2013). To find the carrying capacity, the estimated results based on the Gordon-Schaefer model in Thuy \& Flaaten (2013) are applied._Given the equation for maximum sustainble harvest; $H_{M S Y}=r K / 4=142,000$ tons, and inserting $r=0.53$, the lowest intrinsic growth rate value reported by Thi et al. (2007) for different anchovy species in southwest Vietnam ${ }^{11}$, into this equation, gives $K=1,071,698$ tons. To determine the value for catchability, the equation $p_{0}=c / q K$ shown by Thuy $\&$ Flaaten (2013) is applied. Here $p_{0}=80 \mathrm{USD} /$ ton is the minimum price that fishermen will accept, derived from the emperical Gordon-Schaefer model estimation, and $c=59,134 \mathrm{USD} / \mathrm{vessel} /$ year is the average cost per vessel over the period_(Thuy and Flaaten, 2013). Inserting these two values and the $K$ value into the $p_{0}$ function gives catchability $q=0.00069$.

\subsubsection{Tourism value $V(m)$}


The estimation of the tourism value of NTB MPA is based on data from a DCE survey carried out in 2015, which was conducted using a convenience sample of 150 Vietnamese tourists visiting the MPA. ${ }^{12}$ The survey aimed at valuing the tourists' willingness to pay (WTP) for an expansion of the NTB MPA core zone, which is represented by four attributes: 1) live hard coral cover, 2) environmental quality represented by visible waste and seascape disturbance, 3) fishermen's job losses, 4) the costs of further protection expressed as the increased boat trip ticket price. At that time, the core zone of the NTB MPA was $16 \mathrm{~km}^{2}$ and the question raised was whether a larger core zone should be implemented. Each choice situation consisted of a status quo of keeping the current state (SQ) and two alternatives with increased MPA core zones. ${ }^{13}$

In this study, as in Xuan et al. (2017), we use the mixed logit model (MXL), which accounts for random taste variation among the individuals, to estimate the parameters of the random utility model (see Table 1), in which the parameters of non-cost variables follow normal distributions and the parameter of the cost variable is fixed. ${ }^{14}$ However, unlike Xuan et al. (2017), our model here includes interaction effects between coral cover and environmental quality as well as between coral cover and job loss variables. ${ }^{15}$ The MXL model is estimated in R using the "gmnl"-package (Sarrias \& Daziano, 2016) and 1000 standard Halton draws.

The resulting estimates are then used to derive the amount of money individuals are willing to pay, or consumer surplus $(C S)$ per individual, for three different management scenarios described in Table $2 .^{16}$

Table 1 is here

Table 2 is here

Each management scenario, represented by a specific RZ size, corresponds to a level of coral cover and environmental quality (see Table 2). ${ }^{18}$ Since we do not have an evaluation of the expanded 
core zone size for an increasing level of coral cover and environmental quality, we have to make assumptions regarding these relationships. The assumed relationship between MPA core zone size and coral cover are based on several NTB biological indicators. Before 1994, the average coral cover in the NTB was recorded to be $30 \%$ (Ben et al., 2015), and was reduced to $13 \%$ on average by 2002, due to human activities (Tuan et al., 2002). The coral cover around Mun island, an important core zone in the NTB MPA, has increased by $50 \%$ after 4 years of protection (Tuan et al., 2005). Moreover, the distribution of coral reefs are mostly along the coast and around the islands within the NTB MPA (i.e. the core and buffer zone of NTB MPA) (Tuan et al., 2005). Hence, we assume that if a part or all of the buffer zone of the NTB MPA is added to the core zone, corresponding to the second and the third management scenarios, respectively, and these areas are properly monitored and regulated, then the coral cover within the NTB MPA could be expected to recover after some years of protection.

Based on the three point estimates of the $C S$ per individual for the three management scenarios in Table 2, we specify a non-linear tourism value function, which depends on the size of the RZ (i.e. RZ size is represented by the level of coral cover and environmental quality) following the natural logarithmic functional form:

$v(m)=b \log (m A)+\theta$

where, $b$ and $\theta$ are estimated to be 14.8 and -37 , respectively $\left(R^{2}=0.9998\right) .{ }^{19} A$ is the total study area (inshore area of Khanh Hoa waters). ${ }^{20}$ Taking the annual number of national tourists visiting the NTB MPA (Xuan et al., 2017), $N=500,000$, and multiplying by $v(m)$, we can derive the total tourism value $V(m)$ as shown in equation 1 .

The parameter values used in the analysis of both bioeconomic models, including their sources, are given in Table 3. 
Table 3 is here

\subsection{Simulation results}

In this section, we apply the software package Mathematica to determine the optimal solutions for both the fishery and integrated bioeconomic MPA models. The results from the former model show that for an MPA size greater than 72 percent of the entire area of Khanh Hoa waters, there would be no incentive to fish, as net profit would be zero or negative (e.g., $\left.p-c /\left(q X_{1}\right) \leq 0\right)$. When the size of MPA declines from $72 \%$ of the entire area of Khanh Hoa waters, the optimal fish stock on the fishing ground, harvest, and net profit increase,_approaching the optimal values of the fishery without an MPA. These results are similar to Conrad (1999) who shows "there would be no rationale for a marine sanctuary in a deterministic world with perfect management”. In other words, creating an MPA increases the biological benefits (e.g. increasing total stock size) but gives less economic benefits to fishermen (e.g. reducing harvest and profit).

For the integrated bioeconomic model, we find the values for the two sub-stocks, harvest, and RZ size for each value of $\alpha$ and then calculate corresponding total net present value as well as the net present values of both the fishery and tourism. The results in our simulation show that an $\alpha$ equal to 0.5 gives the highest total discounted value. This implies that the optimal management of the multiple uses of the MPA should put equal weight on the management preferences of the two stakeholders, fishermen and tourists.

With $\alpha=0.5$, there exists two positive steady-state equilibria where $\left(X_{1}^{*} ; X_{2}^{*} ; m^{*} ; Y^{*}\right)$ equals $(536,767 ; 193,121 ; 0.22 ; 120,182)$ and $(312,510 ; 734,780 ; 0.69 ; 12,444)$. However, the former equilibrium is locally asymptotically stable while the latter is unstable. Hence, the former 
equilibrium is a unique singular solution for the optimal control problem of the integrated bioeconomic model, and is used for reporting and discussing the model results. Table 4 presents the numerical simulation results from the two bioeconomic models of MPAs, the fishery and integrated models.

Table 4 is here

Contrary to the bioeconomic fisheries MPA model which suggests that it is not economically viable to establish an MPA with fishery management goals, the integrated model shows that an $\alpha$ level of 0.5 and an MPA size of $22 \%$ of the entire of Khanh Hoa waters maximizes the total joint discounted value from the anchovy fishery and tourism sectors. The suggested optimal RZ size of $22 \%$ reduces the current anchovy fishing effort (year 2011) by $45 \%$ in order to secure the optimal yield level which here has been estimated to be 120,182 tons. $^{22}$ Though the discounted fishery value in the integrated model is less than in the fishery model due to the expansion of RZ size, the total discounted value is substantially increased. The added tourism value does not only compensate for losses in the fishery, but it also contributes to the dramatic increase in total value. A sensitivity analysis for all parameters with direct impact on the outputs is carried out in order to study the model robustness via effects of small changes in each parameter on the resulting values of the optimal variables in the model (see Table 5). These changes are presented as elasticities, or the ratio of percentage change in the values of output variables to $10 \%$ change in the parameter values in the neighborhood of the initial values.

\section{Table 5 is here}

The sensitivity analysis shows that the optimal RZ size and stock size in the HZ are robust to the changes in all parameter values, while the stock size in the RZ is sensitive to change in the fish price. The harvest is highly dependent on the carrying capacity. As could be expected, the change 
in discount factor has a significant effect on the magnitude of all kinds of discounted profits. A change in most fisheries biological and economic parameter values has significant effects on the net present value of the fishery, while the net present value of tourism is sensitive to the changes in tourism parameter values. However, the total net present value is robust to changes in all parameter values, except for $b$. Interestingly, the model is robust to the most uncertain parameter: the dispersal of fish. The optimal $\alpha$ is even more robust, as it does not react at all to the $10 \%$ change in the parameters, and we have therefore not included it in the sensitivity analysis table.

\section{Discussion and Conclusion}

Our results suggest that equal management preferences $(\alpha=0.5)$ for the two sectors, fisheries and tourism, and an optimal RZ size of $22 \%$ (i.e. approximately $625 \mathrm{~km}^{2}$ ) of the nearshore waters of Khanh Hoa province are required in order to achieve the highest total discounted value. The suggested RZ size is much larger than the present NTB MPA core zone $\left(16 \mathrm{~km}^{2}\right.$ or equivalent to $0.56 \%$ of Khanh Hoa waters), and indeed larger than the whole NTB MPA $\left(160 \mathrm{~km}^{2}\right)$. However, one should note that the current NTB MPA was established based on the characteristics of the NTB with its' $507 \mathrm{~km}^{2}$ area, and the current MPA core zone is therefore $3.2 \%$ of the NTB area. The suggested optimal RZ size could be laid out as a network of no-take zones within Khanh Hoa waters for the purpose of biodiversity conservation, sustainable resource use and tourism development. For instance, the expansion of the RZ within the NTB area can potentially be a small proportion of the total suggested RZ size, e.g. for instance $22 \%$ of NTB area or approximately an

increased area of $110 \mathrm{~km}^{2} .{ }^{23}$ The remaining RZ increase could be located in different parts of Khanh Hoa waters, i.e. Van Phong and Cam Ranh Bays, where there exist similar characteristics 
regarding ecosystems, biodiversity, and tourism attractiveness as in NTB (Latypov \& Selin, 2012;

Son et al., 2008; Long et al., 2014; Phung et al., 2002; Quang, 2008).

Our results also indicate that the existing management preferences being applied in Khanh Hoa province, i.e. with a substantially smaller MPA than is optimal, puts much more weight on the fishery sector than on that of the tourism sector. For instance, the current MPA core zone of $0.56 \%$ of Khanh Hoa waters implies that an $\alpha$ level of 0.02 is chosen. This results in an economic loss (i.e., the optimal total NPV declines by $42 \%$ ) due to substantially lower tourism values than what is possible with a different prioritization, or a larger MPA (i.e., the optimal tourism NPV declines by $84 \%$ ), though there is an increase in fisheries' profit due to a reduction in the MPA core zone size (i.e., the optimal fisheries' NPV increases by $36 \%$ ). ${ }^{24}$ Hence, our analysis shows that management in Khanh Hoa province, despite MPA implementation, still prioritizes fisheries ahead of tourism to a large degree, and at a substantial cost, quite contrary to much of the MPA research argument in the literature worldwide. Indeed, our results raise the question whether fisheries interests are being given too much preference, when the total economic value of tourism and fisheries are included.

Another issue pointed out in this study is that though an MPA can be optimal in a multiple use context, the distributional effects of MPAs are exposed, e.g. enlarging the MPA size will increase the conservation and tourism benefits but reduce the benefit from fisheries, presenting potential economic conflicts among resource users. MPA-based tourism development may, however, impose negative effects on biodiversity conservation, causing conflicts between tourism/recreation and conservation goals. Similar results are also suggested by Lee \& Iwasa (2011). Milazzo et al. (2002) indicate that the intensive and unregulated tourism development in MPAs is causing severe threats to marine organisms and habitats at the local scale. This affects directly the effectiveness 
of MPAs as regards biodiversity conservation and hence indirectly fisheries. These economic conflicts are the main reasons of the social "failures" of MPAs as indicated in the literature worldwide (Christie, 2004; Oracion et al., 2005). It is therefore suggested that a multi-use purpose for MPAs (i.e., fish, tourism, and marine conservation) may not induce conflict of interest, but rather result in synergistic interactions if the often poor, local residents are assured benefits from more than one ecosystem service in a sustainable fashion (i.e., fishers are included in tourism activities) (Lopes et al., 2015).

As in the current case of the NTB MPA with open access fisheries outside the MPA, tourism development in general may put more pressure on harvests both directly (e.g. tourists as anglers) and indirectly (e.g. through fish consumption), and hence reduce the fish stock at the local scale. Still, the negative effects of tourism are most probably much smaller than the effects open access fisheries impose on the fish stocks. Therefore, the controlled harvest policies suggested in this study for fishing outside the MPA, can help secure a sustainable level of fish resources. To soften the negative economic impacts of MPA policies on local fishers, revenue accrued from MPAbased tourism can be used partly to compensate for the losses of fishers due to extractive restrictions or fishing closures, through a "payment for environmental services" scheme (Schuhmann et al., 2013; Lopes et al., 2015). Local fishers could also receive direct and indirect financial support for alternative income generation as carried out during the initial period of the NTB MPA establishment (Thu et al., 2005), allowing free attendance in different courses that provide knowledge and skills for new occupations such as handicrafts and animal husbandry. Some tourism regulations (e.g. entrance fees and quotas) may limit the number of tourists visiting the place, so a threshold of environmental damage is not exceeded. Other strategies, such as education and training, can also be implemented to manage tourism impacts on marine 
environments. The success of an MPA depends largely on how the MPA is designed and managed in order to meet the multiple goals of conservation and economic development for local communities (Lopes et al., 2015).

As indicated in our simulation, the NPV from tourism is higher than that of the anchovy fishery, though there are some caveats. Firstly, the tourism value is shown to be highly dependent on both number of tourists visiting the NTB MPA, $N$, and the slope parameter, $b$, of the tourism value function (see Table 5). Concerning the change in number of tourists or tourism demand, this may depend on the increase in boat trip ticket price and the improvement in marine environmental quality within the MPA. As we do not have any data on price- and environment-elasticities for this type of service, we are not able to estimate changes in tourism demand due to a change in MPA management policies. Moreover, the DCE survey for tourists is conducted only in the NTB MPA, while the study site is the whole of Khanh Hoa waters where there exists alternative tourism sites, which may need to be protected as suggested in this study. Hence, if the DCE survey had been conducted in these areas, the number of tourists willing to pay for the potential MPAs may have increased. On the other hand, the value of the estimated slope parameter, $b$, is negatively affected by the assumption of expanding RZ sizes and positively by the estimated WTPs values. The latter is likely to be upwards biased due to the hypothetical nature of the payment mechanism used in the DCE method (Birol et al., 2006), and thus it is often suggested as a reference for upper bound values of the tourism benefit generated by the MPA. Therefore, the actual value of the estimated parameter, $b$, is expected to be lower.

Secondly, it should be noted that only the anchovy fishery is taken into account in this study, instead of the whole multi-species complex which is representative of Khanh Hoa fisheries. Therefore, if these expressed elements are taken into account, the magnitude of the optimal 
variables may well be changed and hence the total NPV of both fisheries and tourism sectors as well as the NPV from each sector, separately.

As indicated in the earlier studies (see Bulte_et al., 1998; Merino et al., 2009), the whole studied area should optimally be protected and dedicated to tourism development if the tourism values or non-use values of MPAs are much larger than the fisheries values. In our simulation, this would be the case if the number of tourists, $N$, is greater than 700,000 , ceteris paribus.

The non-use and alternative values of MPAs are beyond the scope of this study and hence not included in the integrated model. Despite this, the framework presented in this study allows for these values to be integrated in the model for an even broader estimation of multiple benefits provided by MPAs, and hence the optimal size of MPA for multiple values could be determined. Furthermore, as mentioned, the DCE survey in this study was only carried out in the NTB MPA while the fishery and the total area analysed encompasses the whole of Khanh Hoa waters. Although benefits transfer of the NTB MPA values can be applied for other locations within Khanh Hoa waters, it still may not reflect fully the tourism values generated by potential protected areas in the total area. This points to the need to conduct more surveys for tourists visiting outside the NTB to obtain a comprehensive overview and provide more complete information for policy makers. Also, the fisheries of Khanh Hoa are multi-species, multi-fleet and multi-gear, and future research should take into account data from other important species than solely anchovies for a proper assessment of extractive values impacted by the MPA. In addition, MPA-based tourism development may reduce the biodiversity conservation effectiveness, causing severe threats to marine organisms and habitats, and hence affecting indirectly fisheries. Future research should take into account these interactions in the bioeconomic model to address the issues around conflicts between resource users. 


\section{Footnotes}

1. The constant price of fish is a reasonable assumption when the species studied is traded in a large world market, of which the local harvest share is small as is the case here, and therefore does not impact price, and therefore fishers accept exogenous market prices.

2. In this optimal control model, with $\alpha=0$, we follow Conrad (1999) where MPA size is not explicitly considered as a control variable, but utilized MPA size is reflected through varying the reserve size, $m$, in the applied analysis.

3. Tourism development in the MPA contributes to the increase in use value of the MPA. However, when there is intensive and unregulated tourism development in MPAs, this can have direct or indirect negative impacts on marine species (e.g. sessile invertebrates) and habitats (i.e. seagrass beds, macroflora) (see Milazzo et al. 2002 for more discussion). If this is the case, a function describing environmental damage could be included in the model to give a broader picture. However, in this study, the empirical data applied in the model comes from the NTB MPA, which we will assume has necessary solutions and regulations to limit the negative effects caused by tourism within the MPA, as indicated by Van (2013). We therefore do not include environmental damage from tourism in this model.

4. Note that we do not use $\alpha$ here in the total net present value function, as the final net present values are only indirectly affected by $\alpha$ via the determination of the optimal stock, MPA and harvest sizes.

5. As current Vietnamese open access fisheries result in many depleted fish populations as well as serious conflicts of interests among fishing groups (Pomeroy et al., 2007), it is imperative to assess 
more appropriate governance and management approaches for the fisheries operating in nearshore waters.

6. Khanh Hoa Department of Capture Fisheries and Resources Protection (DECAFIREP), 2015.

7. Khanh Hoa Deparment of Statistics.

8. Khanh Hoa Department of Culture, Sports and Tourism.

9. On 9/12/2014, the Khanh Hoa government issued some new regulations for the NTB MPA. Firstly, The NTB MPA core zone was expanded and named a strictly protected area; the buffer zone is also renamed as the ecological rehabilitation zone. Secondly, fishing is not allowed in either area. However, in this paper we use the secondary data before 2011 so we still keep the former NTB MPA scheme for our analysis.

10. Source: NTB Border Defense, 2015

11. Thi et al. (2007) report that the intrinsic growth rates of anchovy species in southeast Vietnamese are relatively high, ranging from 0.53 to 0.90 per year. We choose the most conservative measure.

12. 77\% of all visitors to the NTB are Vietnamese tourists (Xuan et al., 2017), where the remainder are largely Chinese and Russian.

13. The survey design is described in detail in Xuan et al. (2017).

14. See Xuan et al. (2017) for the specification of the model, the discussion on selecting the distribution of random parameters, and measurement of consumer surplus, in detail.

15. It is possible that tourists' WTP for coral cover may be influenced by their preferences for environmental quality and fishermen job loss, we therefore include the interaction effects in the model to estimate the tourism value of different MPA management policies. 
16. The estimated parameters of the interactive variables between coral and job loss are excluded when calculating $C S$ for different management scenarios, due to their being statistically insignificant. As indicated by Armstrong et al., (2017), all coefficient, significant or insignificant, could be included, this would however give a higher standard error.

17. The exchange rate is 1 USD equaling 20,828 VND and 22,547 VND in 2011 and in 2015, respectively (State Bank of Vietnam, 2016). The mean CS values are deflated back to 2011 using the consumer price index (CPI) reported by the World Bank (2016).

18. Though the good valued is a hypothetical core zone expansion of the NTB MPA, we chose not to include the MPA core zone size as an attribute, due to causality. That is, the increase in coral cover, environmental quality, and fishermen's job losses can be seen as a result of an increase in the MPA core zone size. Hence, inclusion of the core zone size attribute may encourage respondents to try to understand the causal relations among attributes and potentially to simplify their decision making process, resulting in a reduction in marginal WTP for the other attributes (Bennett and Blamey, 2001), which are indicated as the most important for tourists choosing to visit the NTB MPA.

19. The value of the estimated parameter, $b$, indicates that when the size of protected area increases $1 \%$, the average consumer surplus per individual increases by 0.148 USD.

20. The study site is Khanh Hoa waters which includes the NTB MPA where the DCE survey took place. Hence the tourism value function will depend on the RZ size which is proportional to the total area of study, i.e. the Khanh Hoa inshore waters.

21. State Bank of VN (http://www.sbv.gov.vn/) 
22. The fishing effort in 2011 reported by Thuy \& Flaaten (2013) was 581 vessels, while the optimal fishing effort calculated from the estimations of this study is $E^{*}=Y^{*} /\left(q X_{I}^{*}\right)=120,182 /(0.00069 * 545,085)=319$ vessels.

23. Though the NTB MPA core zone size has been expanded in recent years, it comes nowhere close to the expansion our results suggest.

24. At the current MPA core zone size $(m=0.56 \%)$, the values of the total NPV, the fisheries' NPV, and the tourism NPV are 366; 300; and 66 million dollars, respectively.

\section{References}

Alban F, Appéré G, Boncoeur J et al (2008) Economic analysis of Marine Protected Areas - A literature review. EMPAFISH Project Booklet 3.

Alexander R (2000) Modelling species extinction - The case for non-consumptive values. Ecological Economics 35: 259-269.

Armstrong C W (2007) A note on the ecological-economic modelling of marine reserves in fisheries. Ecological Economics 62(2): 242-250.

Armstrong C W, Kahui V, Vondolia G K et al (2017) Use and non-use values in an applied bioeconomic model of fisheries and habitat connections. Marine Resource Economics 2(4): 351369.

Badalamenti F, Ramos A A, Voultsiadou E et al (2000) Cultural and socio-economic impacts of Mediterranean marine protected. Environmental Conservation 27(2): 110-125.

Balmford A, Gravestock P, Hockley N et al (2004) The worldwide costs of marine protected areas. Proceedings of the National Academy of Sciences of the United States of America 101(26): 9694-9697 
Ben H X, Tuyen H T, Hoàng P K et al (2015) The status, tendency, and ability to recover coral biodiversity in the Nha Trang Bay. In Vietnamse: Hiện trạng, xu thế và khả năng phục hồi đa dạng sinh học rạn san hô ở vịnh Nha Trang. Institute of Oceanography, Vietnam Academy of Science and Technoloy 21(2): 176-187.

Bennett J, Blamey R (2001) The choice modelling approach to environmental valuation. Edward Elgar Publishing.

Birol E, Karousakis K, Koundouri P (2006) Using a choice experiment to account for preference heterogeneity in wetland attributes: the case of Cheimaditida wetland in Greece. Ecological Economics 60(1): 145-156.

Boncoeur J, Alban F, Ifremer O G et al (2002) Fish, fishers, seals and tourists: Economic consequences of creating a marine reserve in a multi-species, multi-activitiy context. Natural Resource Modeling 15(4): 387-411.

Bulte E, Folmer H, Heijman W (1998) Dynamic and static approaches to mixed good management: The case of minke whales in the Northeast Atlantic. European Review of Agricultural Economics 25(1); 73-91.

Christie P (2004) Marine Protected Areas as Biological Successes and Social Failures in Southeast Asia. American Fisheries Society 42: 155-164.

Clark C W, Munro G R (1975) The economics of fishing and modern capital theory: a simplified approach. Journal of Environmental Economics and Management 2(2): 92-106.

Conrad J M (1999) The bioeconomics of marine sanctuaries. Journal of Bioeconomics 1(2): 205217.

Dung L D (2009) Nha Trang Bay marine protected area, Vietnam: Initial trends in coral structure and some preliminary linkages between these trends and human activities (2002-2005). Aquatic 
Ecosystem Health \& Management 12(3): 249-257.

FAO (2012) Overview of the world' s anchovy sector and trade possibilities for Georgian anchovy products. Eurofish International Orgnization, (February).

Foley N S, Armstrong C W, Kahui V et al (2012) A Review of Bioeconomic Modelling of Habitat-Fisheries Interactions. International Journal of Ecology 2012.

Horan R D, Shortle J S (1999) Optimal management of multiple renewable resource stocks: An application to Minke whales. Environmental and Resource Economics 13(4): 435-458.

Kim Anh N T, Thuy N T T, Flaaten O (2007) Income sharing systems among purse seine fishermen in Cam Ranh and Nha Trang, Vietnam. Fish for the people 5.

Latypov Y Y, Selin N I (2012) The composition and structure of a protected coral reef in Cam Ranh Bay in the South China Sea. Russian Journal of Marine Biology 38(2): 112-121.

Lee J H, Iwasa Y (2011) Tourists and traditional divers in a common fishing ground. Ecological Economics 70(12): 2350-2360.

Long N V, Tuan V S, Hoang P K et al (2014) Coral Reefs in Van Phong Bay, Khanh Hoa Province: Status and Management Perspectives. Collection of Marine research works 20: 121134.

Lopes P F M, Pacheco S, Clauzet M et al (2015) Fisheries, tourism, and marine protected areas: Conflicting or synergistic interactions?. Ecosystem Services 16: 333-340.

Merino G, Maynou F, Boncoeur J (2009) Bioeconomic model for a three-zone Marine Protected Area: a case study of Medes Islands (northwest Mediterranean). ICES Journal of Marine Science: Journal du Conseil 66(1): 147-154.

Milazzo M, Chemello R, Badalamenti F et al (2002) The Impact of Human Recreational Activities in Marine Protected Areas : What Lessons Should Be Learnt in the Mediterranean 
Sea?. Marine Ecology 23(1): 280-290.

Moyle B J, Evans M (2008) Economics development options for island states: The case of whale-watching. The International Journal of Research into Island Cultures 2(1): 41-58.

Munro G R (1979) The optimal management of transboundary renewable resources. Canadian Journal of Economics 355-376.

Munro G R, Scott A D (1985) The economics of fisheries management. Handbook of natural resource and energy economics 2: 623-676.

Oracion E G, Miller M L, Christie P (2005) Marine protected areas for whom? Fisheries, tourism, and solidarity in a Philippine community. Ocean \& Coastal Management 48: 393-410. Phung N H, Quang V V, Hoa T T H (2002) The fish eggs and larvae in coastal water of Khanh Hoa province. Collection of Marine Research Works XII 205-214.

Pomeroy R, Parks J, Pollnac R et al (2007) Fish wars: Conflict and collaboration in fisheries management in Southeast Asia. Marine Policy 31(6): 645-656.

Quang V V (2008) Morphological development, distribution and transport of fish eggs and larvae of anchovy, blue stripes (Encrasicholina punctifer Fowler, 1938) in Khanh Hoa - Binh Thuan water. In Vietnamese: Đặc điểm hình thái phát triển, sự phân bố và vận chuyển của trứng cá và cá bột loài cá cơm sọc xanh (Encrasicholina punctifer Fowler, 1938) vùng biển Khánh Hòa - Bình Thuận. Doctoral Thesis.

Rakitin A, Kramer D L (1996) Effect of a Marine Reserve On the Distribution of Coral Reef Fishes in Barbados. Marine Ecology Progress Series 131: 97-113.

Rodwell L D, Barbier E B, Roberts C M et al (2003) The importance of habitat quality for marine reserve fishery linkages. Canadian Journal of Fisheries and Aquatic Sciences 60(2): 171181. 
Rondeau D (2001) Along the way back from the brink. Journal of Environmental Economics and Management 42(2): 156-182.

Sarrias M, Daziano R (2016) Multinomial Logit Models with Continuous and Discrete Individual Heterogeneity in R: The gmnl Package. gmnl Package in R (March) 1-41.

Schnier K (2005) Biological "hot spots" and their effect on optimal bioeconomic marine reserve formation. Ecological Economics 52(4): 453-468.

Schuhmann P W, Casey J F, Horrocks J A et al (2013) Recreational SCUBA divers' willingness to pay for marine biodiversity in Barbados. Journal of environmental management 121: 29-36. Skonhoft A (2007) Economic modeling approaches for wildlife and species conservation. Ecological Economics 62(2): 223-231.

Skonhoft A, Johannesen A B (2000) On the problem of over- grazing (In Norwegian: Om overbeitingsproblemet). Norsk Økonomisk Tidsskrift 114(2): 151-168.

Son T P H, Ha L T T, Ben H X et al (2008) A survey of distribution of coral reef ecosystems of Khanh Hoa coastal water as fundamental source for protection, restoration, and sustainable use. Applied Research. Instititue of Oceanography.

Thi D V, Bat N K, Nguyen D V et al (2007) Anchovy stock assessment in southwest Vietnam, and the solutions for sustainable management. In Vietnamese: Đánh giá trữ lượng cá cơm vùng biển Tây Nam Bộ và đề xuất các biện pháp khai thác hợp lý. Research Institute of Marine Fisheries, Hai Phong, Vietnam.

Thu H V T, Linh T N M, Duyen C T T et al (2005) Socio-economic impact assessment of the Hon Mun MPA project on local communities within the MPA. Hon Mun Authority, Nha Trang 54.

Thuy P T T, Flaaten O (2013) The Backward-Bending Supply Curve in Fisheries-Revisited. 
Journal of Sustainable Development 6(6): 15.

Tuan V S, DeVantier L M, Long N V et al (2002) Marine and Coastal Habitats of Hon Mun Marine Protected Area, Nha Trang Bay, Vietnam Baseline Survey, March-April 2002. Hon Mun Marine Protected Area Pilot Project Biodiversity Technical Report 5.

Tuan V S, Long N, Tuyen H et al (2005) Marine and Coastal Habitats of Nha Trang Bay Marine Protected Area, Khanh Hoa , Viet Nam: Reassessment 2002 - 2005. Biodiversity Report No 13. Van D H. (2013) Solutions to improve the management of the exploitation and protection of fisheries resources in Nha Trang Bay Marine Protected Area. In Vietnamese: Giải pháp nâng cao hiệu quả công tác quản lý khai thác và bảo vệ nguồn lợi thủy sản trong khu bảo tồn biển. Master Thesis.

Viet D D H, Vinh V D, Chien P V et al (2014) Simulating the distribution of fish eggs and larvae within the Nha Trang Bay marine protected area. In Vietnamese: Bước đầu mô phỏng sự phát tán trứng cá, cá bột nhóm cá rạn san hô khu bảo tồn biển Vịnh Nha Trang. Journal of Marine Science and Technology. 14(4): 368-377.

Xuan B B, Sandorf E D, Aanesen M (2017) Informing management strategies for a reserve:

Results from a discrete choice experiment survey. Ocean \& Coastal Management 145: 35-43. World Bank. http://data.worldbank.org/indicator/FP.CPI.TOTL?locations=VN 

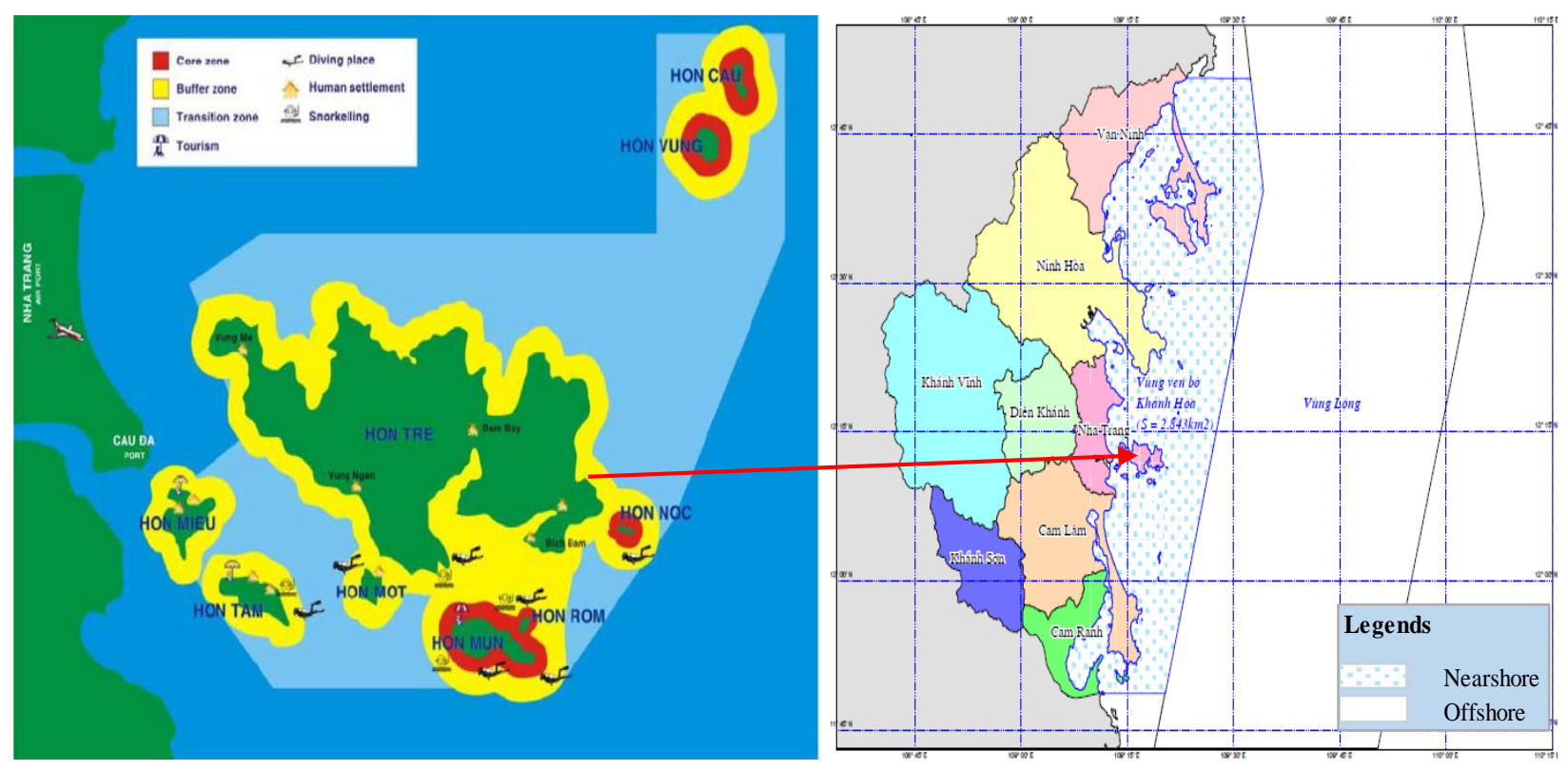

Figure 1. The zoning scheme of NTB MPA in 2001 (Tuan et al., 2005) and the Map of Khanh

Hoa, Vietnam. 
Table 1. MXL model estimate results

\begin{tabular}{|c|c|c|}
\hline Attributes & $\begin{array}{c}\text { Mean } \\
\text { (standard error) }\end{array}$ & $\begin{array}{l}\text { Standard deviation } \\
\text { (standard error) }\end{array}$ \\
\hline Cost & $-0.00624(0.00182) * * *$ & \\
\hline Coral & $0.05709(0.01815)^{* *}$ & $0.11103(0.01557) * * *$ \\
\hline Coral*med.env & $0.05355(0.00754) * * *$ & $0.03408(0.00907) * * *$ \\
\hline Coral*high.env & $0.11205(0.01708) * * *$ & $0.06082(0.01456) * * *$ \\
\hline Coral*small.loss & $-0.00616(0.01205)$ & $0.05734(0.02422)^{*}$ \\
\hline Coral*med.loss & $0.00728(0.01115)$ & $0.07828(0.01502) * * *$ \\
\hline Coral*large.loss & $-0.00414(0.00966)$ & $0.05208(0.01367) * * *$ \\
\hline \multicolumn{3}{|l|}{ Model characteristics } \\
\hline Adjusted Pseudo $\mathrm{R}^{2}$ & & 0.142 \\
\hline Log-likelihood at convergence & & -841.25 \\
\hline Number of observations & & 900 \\
\hline Number of parameters estimated & & 7 \\
\hline AIC & & 1708.49 \\
\hline
\end{tabular}


Table 2. Consumer surplus in USD per individual resulting from the MXL model ${ }^{17}$

\begin{tabular}{cccc}
\hline \multirow{2}{*}{$\begin{array}{c}\text { Management } \\
\text { scenarios }\end{array}$} & \multicolumn{2}{c}{ Attributes } & Mean CS \\
\cline { 2 - 3 } & Coral cover & Environment quality & (95\% confident interval) \\
\hline Small RZ (SQ) & $13 \%$ & Low & 4.8 \\
$\left(16 \mathrm{~km}^{2}\right)$ & $20 \%$ & Medium & $(2.7-7.4)$ \\
\hline Medium RZ & & & $(10.5-24.0)$ \\
$\left(30 \mathrm{~km}^{2}\right)$ & $30 \%$ & High & 31.6 \\
\hline Large RZ & & & $(24.4-55.3)$ \\
$\left(80 \mathrm{~km}^{2}\right)$ & & & \\
\hline
\end{tabular}


Table 3. Biological and economic parameters of the anchovy purse seine fishery and tourism sector.

\begin{tabular}{ccrl}
\hline Parameter & Unit & Measure & \multicolumn{1}{c}{ Source/explanation } \\
\hline$\delta$ & & 0.07 & Average interest rate during last 5 years ${ }^{21}$ \\
$\gamma$ & & 100,000 & Guesstimated \\
$r$ & Year $^{-1}$ & 0.53 & Thi et al. (2007) \\
$K$ & Tons & $1,071,698$ & Calculated from Thuy \& Flaaten (2013) \\
$p_{0}$ & USD/Ton & 80 & Thuy \& Flaaten (2013) \\
$p$ & USD/Ton & 288 & Thuy \& Flaaten (2013) \\
$q$ & Boat ${ }^{-1}$ & 0.00069 & Calculated from Thuy \& Flaaten (2013) \\
$c$ & USD/vessel/year & 59,134 & Thuy \& Flaaten (2013) \\
$b$ & & 14.8 & Estimated from own valuation study data \\
$A$ & Km ${ }^{2}$ & 2843 & Map of Khanh Hoa province \\
$N$ & Person & 500,000 & Xuan et al. (2017) \\
\hline
\end{tabular}


Table 4. Simulation results for the steady-state equilibria from the two optimal control models.

\begin{tabular}{cllrr}
\hline Output & Description & Unit & \multicolumn{2}{c}{ Bioeconomic model: } \\
variable & & & Fishery & Integrated \\
\cline { 3 - 4 }$X_{1}^{*}$ & Stock size in fishing ground & Tons & & 536,767 \\
$X_{2}^{*}$ & Stock size in MPA & Tons & & 193,121 \\
$X^{*}$ & Total stock size & Tons & 646,442 & 729,888 \\
$Y^{*}$ & Harvest & Tons & 135,951 & 120,182 \\
$m^{*}$ & MPA size & & 0 & 0.22 \\
$\alpha^{*}$ & Weighting parameter & & 302 & 0.5 \\
$N P V^{*}$ & Total net values & & 302 & 636 \\
$N P V_{f}^{*}$ & Net profit from fishery & Million USD & & 220 \\
$N P V_{v}^{*}$ & Net value from tourism & Million USD & & 416
\end{tabular}


Table 5. Sensitivity analysis of the integrated model. Sensitive results are marked in bold and negative numbers in parentheses.

\begin{tabular}{|c|c|c|c|c|c|c|c|}
\hline \multirow{2}{*}{$\begin{array}{c}10 \% \\
\text { increase in }\end{array}$} & \multicolumn{7}{|c|}{$\%$ change in optimal values } \\
\hline & $X_{1}^{*}$ & $X_{2}^{*}$ & $Y^{*}$ & $m^{*}$ & $N P V^{*}$ & $N P V_{f}^{*}$ & $N P V_{v}^{*}$ \\
\hline$\delta$ & $(0.46)$ & $(0.10)$ & 0.38 & 0.08 & (11.06) & (11.21) & (10.98) \\
\hline$r$ & 1.39 & $(4.73)$ & 9.62 & $(5.33)$ & 3.34 & 11.18 & $(1.34)$ \\
\hline$K$ & 8.52 & $(0.45)$ & 13.59 & $(9.73)$ & 7.47 & 22.06 & $(2.42)$ \\
\hline$\gamma$ & $(0.12)$ & $(0.64)$ & 0.58 & 0.56 & 0.24 & 0.42 & 0.14 \\
\hline c & 3.40 & 2.45 & $(3.84)$ & 0.80 & $(4.34)$ & (14.03) & 0.20 \\
\hline$p$ & $(1.79)$ & (12.00) & 4.42 & $(8.84)$ & 7.71 & 22.32 & $(2.20)$ \\
\hline$q$ & $(3.46)$ & $(1.62)$ & 2.85 & $(0.11)$ & 3.88 & 10.55 & $(0.03)$ \\
\hline$b$ & $(1.82)$ & 9.72 & $(2.21)$ & 8.45 & 10.69 & $(4.57)$ & 17.24 \\
\hline$A$ & - & - & - & - & 1.71 & - & 2.60 \\
\hline$N$ & $(1.82)$ & 9.72 & $(2.21)$ & 8.45 & 6.82 & $(4.57)$ & 11.99 \\
\hline
\end{tabular}

